\title{
Car sunshade-induced craniofacial injury: a case report
}

Mahdi Sharif-Alhoseini ${ }^{1}$, Hadi Khatibi ${ }^{2}$, Mojtaba Chardoli ${ }^{3}$ and Vafa Rahimi-Movaghar ${ }^{1,4^{*}}$

\begin{abstract}
Introduction: We report the case of a man who sustained a craniofacial injury after spontaneous lateral airbag deployment resulting in his face being struck by a car sunshade. This highlights the potential damage that can be caused by any object placed between a lateral airbag and a car occupant.

Case presentation: We report the case of a 33-year-old Caucasian man who was the driver in a frontal collision. He had opened the car sunshade and turned it $90^{\circ}$ towards the left. As he was driving, he struck a bus, causing the driver's lateral airbag to spontaneously deploy. The airbag pushed the sunshade against his face and injured him.

Conclusions: Car sunshades can cause significant craniofacial injury. We suggest that sunshade design must be improved to reduce the risk of potential injuries to car occupants. We recommend a new, safer sunshade design.
\end{abstract}

\section{Introduction}

Although there are reports of injuries caused by airbags [1-5], we are unaware of any literature describing injuries from car sunshades. We report a case of severe craniofacial injury after spontaneous lateral airbag deployment that caused the sunshade to strike the driver's head. We also discuss the mechanism of sunshade induced injuries.

\section{Case presentation}

A 33-year-old Caucasian man was referred to ShahidRasi Hospital in Shahindezh (West Azarbaijan province, Northwestern Iran) after a motor vehicle crash. He was driving on a two-way mountain road in a south-north direction before sunset. Because of sunlight, he opened the car sunshade and turned it $90^{\circ}$ towards the left. As he was driving at $60 \mathrm{~km} /$ hour on a sharp curve in the road, his car suddenly hit a bus coming from the opposite direction. The driver's lateral and steering wheel airbags spontaneously deployed. The lateral airbag pushed the sunshade against his face so hard that the sunshade was completely deformed and caused injury to the left side of the face (Figure 1). He suffered abrasions on the left side of the face, retinal damage, and fractures of the

\footnotetext{
* Correspondence: v_rahimi@sina.tums.ac.ir

${ }^{1}$ Sina Trauma and Surgery Research Center, Sina Hospital, Tehran University of Medical Sciences, Tehran, Iran

Full list of author information is available at the end of the article
}

skull base and nose. He also suffered superficial right forearm burns due to the rupture of the steering wheel airbag. His left hand was caught in the steering wheel, resulting in left distal radial and ulnar fractures. He underwent operative fixation of his nose and wrist factures and was referred to an ophthalmologist for evaluation of his retinal injury.

\section{Discussion}

Airbag-associated injury occurs in $43 \%$ of airbag deployments [6]. Typically, airbag-related injuries are minor, but severe or fatal injuries are also reported [7]. Minor injuries such as abrasions, contusions and lacerations are usually detected on the face, neck, chest, and upper extremities $[8,9]$. Airbag deployment also releases hightemperature gases, including nitrogen and carbon dioxide, and produces sodium hydroxide, a very irritating alkaline material, which can cause superficial and even full thickness burns $[10,11]$. As demonstrated by this case, an opened and turned sunshade can also be a potentially dangerous object between a lateral airbag and a driver or passenger.

\section{Conclusions}

When the lateral airbag deploys, it pushes the sunshade onto the occupant's face and head. Consequently, it seems that vehicles with side airbags should not have moveable 

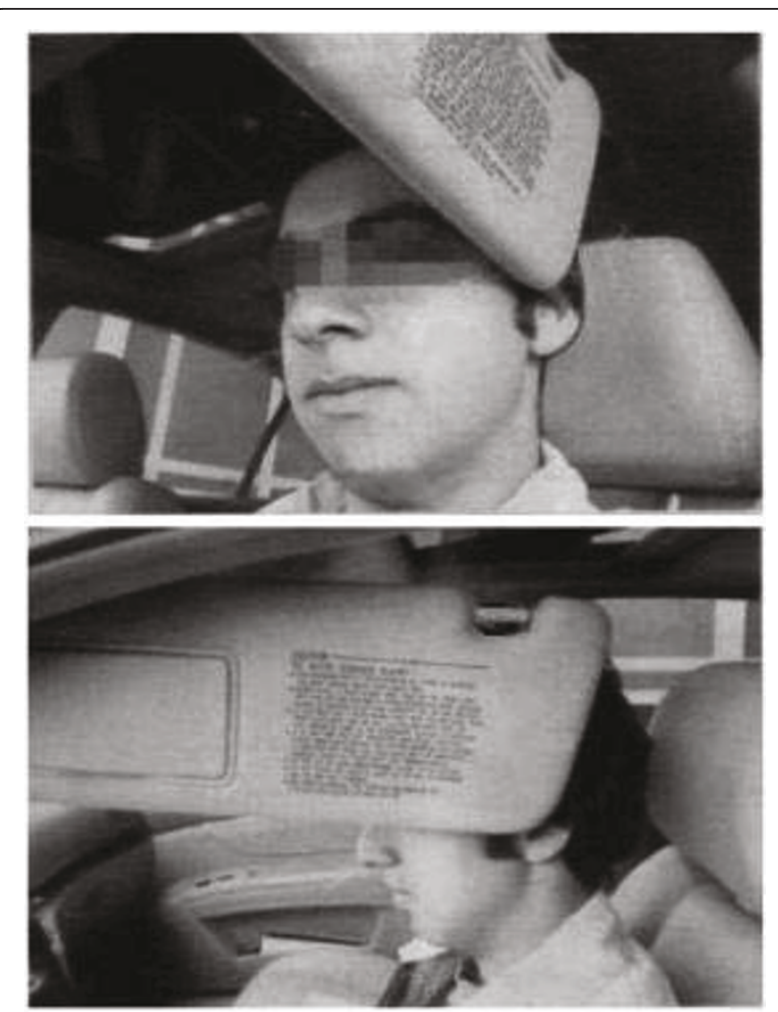

Figure 1 Lateral airbag deployment pushed the sunshade against driver's face. The sunshade was completely deformed and caused injury to the left side of the temporal skull, orbit, face, and nose. This figure is a model, and the model has provided informed written consent to his image being used.

sunshades that can be placed in the lateral position. We suggest the design and use of sunshades that do not project into the vehicle or the use of sunglasses.

\section{Consent}

Written informed consent was obtained from the patient for publication of this case report and any accompanying images. A copy of the written consent is available for review by the Editor-in-Chief of this journal.

\section{Author details}

'Sina Trauma and Surgery Research Center, Sina Hospital, Tehran University of Medical Sciences, Tehran, Iran. ${ }^{2}$ Donya-e-Khodro Weekly, Tehran, Iran. ${ }^{3}$ Emergency Department of Hazrat-e-Rasool Hospital, Tehran University of Medical Sciences, Tehran, Iran. ${ }^{4}$ Research Centre for Neural Repair, University of Tehran, Tehran, Iran.

\section{Authors' contributions}

MS wrote the case report and performed the literature search. HK wrote the Farsi version of the draft and organized the photographs. MC and VRM designed the methodology, discussed, and edited the draft. All authors read and approved the final manuscript.

\section{Competing interests}

The authors declare that they have no competing interests.

Received: 7 June 2010 Accepted: 10 May 2011 Published: 10 May 2011

\section{References}

1. Nguyen CS, Chase DM, Wing DA: Severe fetal skull fracture and death subsequent to a motor vehicle crash with frontal airbag deployment J Trauma 2009, 67:E220-E221.

2. Bard MR, Shaikh S, Pestaner J, Newell MA, Rotondo MF: Direct fetal injury due to airbag deployment and three-point restraint. J Trauma 2009, 67: E98-E101.

3. Huber $C D$, Lee $J B$, Yang $K H$, King Al: Head injuries in airbag-equipped motor vehicles with special emphasis on AIS 1 and 2 facial and loss of consciousness injuries. Traffic Inj Prev 2005, 6:170-174.

4. Yoganandan N, Pintar FA, Zhang J, Gennarelli TA: Lateral impact injuries with side airbag deployments - a descriptive study. Accid Anal Prev 2007, 39:22-27.

5. Monkhouse SJ, Kelly MD: Airbag-related chest wall burn as a marker of underlying injury: a case report. J Med Case Rep 2008, 2:91.

6. Serra C, Delattre $O$, Despeignes $R L$, Cousin A: Upper limb traumatic lesions related to airbag deployment: a case report and review of literature. J Trauma 2008, 65:704-707.

7. Usumoto Y, Hikiji W, Kudo K, Tsuji A, Ikeda N: An unusual case of fatal airbag injury. Fukuoka lgaku Zasshi 2008, 99:225-229.

8. Subash M, Manzouri B, Wilkins M: Airbag-induced chemical eye injury. Eur J Emerg Med 2010, 17:22-23.

9. Sato $Y$, Ohshima T, Kondo T: Air bag injuries- a literature review in consideration of demands in forensic autopsies. Forensic Sci Int 2002, 128:162-167.

10. Heimbach D: Full-thickness burn to the hand from an automobile airbag. J Burn Care Rehabil 2000, 21:288-289.

11. Corazza M, Trincone S, Zampino MR, Virgili A: Air bags and the skin. Skinmed 2004, 3:256-258.

doi:10.1186/1752-1947-5-175

Cite this article as: Sharif-Alhoseini et al:: Car sunshade-induced craniofacial injury: a case report. Journal of Medical Case Reports 2011 5:175.

\section{Submit your next manuscript to BioMed Central and take full advantage of:}

- Convenient online submission

- Thorough peer review

- No space constraints or color figure charges

- Immediate publication on acceptance

- Inclusion in PubMed, CAS, Scopus and Google Scholar

- Research which is freely available for redistribution
Biomed Central 